\title{
Professional and Personal Use of Reflection by Engineering Faculty, Students, and Practitioners
}

\section{Dr. Adam R. Carberry, Arizona State University}

Dr. Adam Carberry is an associate professor at Arizona State University in the Fulton Schools of Engineering, The Polytechnic School. He earned a B.S. in Materials Science Engineering from Alfred University, and received his M.S. and Ph.D., both from Tufts University, in Chemistry and Engineering Education respectively. Dr. Carberry was previously an employee of the Tufts' Center for Engineering Education \& Outreach.

\section{Dr. Trevor Scott Harding, California Polytechnic State University, San Luis Obispo}

Dr. Trevor S. Harding is Professor and Chair of Materials Engineering at California Polytechnic State University where he teaches courses in synthetic and biological polymers, materials selection, and fracture mechanics. He has conducted educational research in the areas of ethical decision making, reflection and innovative pedagogies for the past 19 years. He serves as Associate Editor of the journal Advances in Engineering Education. He has served as division chair for the Community Engagement Division and Materials Division of ASEE. Dr. Harding was invited to deliver a workshop on Ethics in the Engineering Curricula at the 2009 NSF Engineering Awardees Conference and to participate in the NSF Project Based Service Learning Summit. He received the 2008 President's Service Learning Award for innovations in the use of service learning at Cal Poly. In 2004 he was named a Templeton Research Fellow by the Center for Academic Integrity. Dr. Harding received both the 1999 Apprentice Faculty Grant and 2000 New Faculty Fellow Award for his contributions to engineering education.

\section{Dr. Patrick J. Cunningham, Rose-Hulman Institute of Technology}

Patrick Cunningham is an Associate Professor of Mechanical Engineering at Rose-Hulman Institute of Technology. During the 2013-14 academic year he spent a sabbatical in the Department of Engineering Education at Virginia Tech. Dr. Cunningham's educational research interests are student metacognition and self-regulation of learning, reflective pedagogies, and faculty development. His disciplinary training within Mechanical Engineering is in dynamic systems and control with applications to engine exhaust aftertreatment.

\section{Dr. Kristine R. Csavina, Colorado School of Mines}

Dr. Kristy Csavina is a Teaching Professor and Assistant Department Head in the Department of Mechanical Engineering at the Colorado School of Mines. She has her bachelors degree in Mechanical Engineering from the University of Dayton and her doctorate in Bioengineering from Arizona State University.

\section{Ms. Michelle Choi Ausman, California Polytechnic State University, San Luis Obispo}

Michelle Choi Ausman is a Liberal Arts and Engineering Studies Bachelors of Arts candidate at California Polytechnic State University, San Luis Obispo. She is concentrating on ethical engineering design and minoring in English and Psychology. She is a Technical Writing Intern at Ernie Ball Music Man in San Luis Obispo, CA. Currently, she is working on the 2Towns Project in Sacramento, California to help redesign the K Street Passageway, as part of her Liberal Arts and Engineering Studies curriculum. In June 2018, she will travel as part of the Cal Poly Service in Action program to work with the people of Lima, Peru to help with efforts in regards to children's health and human services.

\section{Diana Lau, California Polytechnic State University, San Luis Obispo}

Diana Lau, a Los Angeles native, is a senior engineering undergraduate at California Polytechnic State University, San Luis Obispo. She is focusing her studies on product design development and packaging engineering. Lau's passion to empower, encourage, and mentor young girls to pursue a STEM education has inspired her to volunteer her time to help at outreach events. She currently serves as an officer for the 


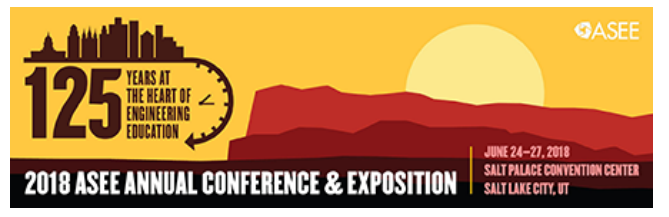

Paper ID \#21568

nationally recognized Society of Women Engineers collegiate section at Cal Poly. Lau hopes that STEM education can also reach and retain people who thrive in non-traditional learning environments; she is actively developing a summer after-school enrichment program that focuses on the benefits of a "flipped classroom" teaching model. Lau will be interning at Northrop Grumman for the summer of 2018. 


\title{
Professional and Personal Use of Reflection by Engineering Faculty, Students and Practitioners
}

\begin{abstract}
Reflection has long been recognized as an integral part of a person's every day and professional and/or academic life. Recently the Consortium to Promote Reflection in Engineering Education (CPREE) has been working to promote reflection across the engineering education community within the United States. The following study leverages the authors' involvement, experiences, and observations within CPREE to capture the use of reflection in professional and personal settings by engineering faculty, students, and practitioners. Researchers from four distinctly different institutions have collected data from 460 engineering participants. Participants were asked to respond to three open-ended prompts eliciting their definitions of reflection in their own words, examples of reflection use in their personal lives, and examples of reflection use in their professional and/or academic lives. These questions were posed to better understand how each group perceives and uses reflection in their personal and professional lives. The results of this study provide valuable insights into the similarities and differences across groups, which can be used to inform how the professional skill of reflection is taught and practiced within engineering curricula.
\end{abstract}

\section{Introduction}

Reflection has long been considered an important aspect of professional practice. Educated practitioners utilize reflection to connect the knowledge of their fields, infuse this knowledge with meaning, and intertwine knowledge with their own personal identities [1-7]. We are reflecting any time we draw on prior experiences and use our interpretations of these experiences to inform our choices and actions to impact the present or future. Grossman further specifies four levels of reflection: content-based reflection, metacognitive reflection, self-authorship reflection, and transformative or intensive reflection [8]. These levels of reflection represent key ways we richly interconnect the knowledge of our fields, infuse it with meaning, and intertwine it with what it means to be who and what we are.

Recently the Consortium to Promote Reflection in Engineering Education (CPREE) and its constituents have made considerable progress in promoting and studying the use of reflection across the engineering education community within the United States [9-16]. Research has observed that the value of reflection within an educational or work environment can vary and that many are not aware of the research and applied professional skills that support reflective practice [15]. These observations lead us to study the relative value that different individuals and constituencies place on reflection [11]. The author's previous work as constituents of CPREE 
suggest a need to differentiate how individuals use and value reflection in their personal lives versus their professional and/or academic lives.

The following study leverages our involvement, experiences, research and observations within CPREE to capture the use of reflection in professional and personal settings by engineering faculty, students, and practitioners. We analyze two fundamental questions:

1. How do engineering educators, students, and practitioners define reflection?

2. How do engineering educators, students, and practitioners use reflection in their personal, professional and/or academic life?

Our purpose in studying these research questions is to inform efforts to improve educational practices in engineering, particularly the role of reflection in engineering work. This paper presents an analysis of participant definitions and uses of reflection within and across groups. The emergent findings provide a better understanding of engineers' use of reflection both in and outside of the classroom or workplace. We assert that by examining this rich set of data, we might ultimately be able to leverage the ways in which practitioners use reflection to help better educate engineering students and better prepare them for a profession that is both more effective and more ethical.

\section{Theoretical Framework \& Background Literature}

Reflection is not a new idea in education. John Dewey laid significant foundations for reflective thinking in the early 1900's [1], which was later distilled by Carol Rodgers into four criteria: 1) making meaning; 2) intentional, systematic, and rigorous thinking; 3) interacting socially; and 4) oriented towards intellectual growth [5]. Making meaning has to do with making connections within and among experiences and knowledge, i.e., the construction of knowledge frameworks through developing relationships. These relationships are developed through an intentional, systematic and rigorous thought process that can be envisioned as a four-step cycle of being present to an experience, describing the experience, analyzing the experience, and responding to the experience with intelligent experimentation [5]. The response then turns into the next experience to continue the cycle. This process bears strong resemblance to the scientific method. The social aspect of reflection serves to refine one's thinking as it requires putting ideas into a coherent and understandable story and opens the ideas to others' examination and critique. Finally, in Dewey's definition, reflection is oriented towards growth, which can be described as a set of attitudes that include whole-heartedness, directness, open-mindedness, responsibility, and readiness [5].

The act of reflecting, in particular self-reflecting, plays a central role in learning. Kolb's experiential learning cycle [17] is comprised of four steps, including reflective observation [18]. 
Zull notes the necessity of these steps for learning to occur, where learning is building physiological connections in the brain [18]. Connections made via reflection play a role in the development and practice of self-regulated learning [19]. Zimmerman's cyclical model of selfregulated learning includes a self-reflection phase that captures the appraisal of learning experiences in the immediate or distant past (performances) and connects the interpretations and lessons to planning (forethought) for future learning experiences. These self-reflections include self-judgements and self-reactions. Self-judgements include evaluation of one's performance against some standard (e.g., class average or some prior performance) and attribution of the cause of the perceived level of performance, whether accurate or inaccurate. Self-reactions include feelings about the performance (e.g., self-satisfaction) and postures adopted to respond to the performance (e.g., adaptive or defensive) [19]. The quality of self-reflections mediates the accrued self-regulatory knowledge and the skillful practice of self-regulated learning due to the cyclical nature of self-regulation.

These reflections, whether broad or focused, have been described as occurring on a continuum of levels with varying depth of self-awareness and sophistication. These levels include contentbased reflection, metacognitive reflection, "self-authorship" reflection, and transformative and intensive reflection [8]. Each level probes deeper into one's own observation of one's thinking. Content-based reflection aids depth of learning. Metacognitive reflection involves examining one's knowledge and regulation of thinking. "Self-authorship" reflection is where "inner states become observed objects rather than lived subjects" [8]. Transformative and intensive reflection cause a change in one's frame of reference. It involves understanding the sources of thinking and behavior as well as the ability to adapt and change. Grossman notes that many students struggle with reflection, especially at the deeper levels, due to failure to engage in reflection or a need to develop and build the capacity for reflection [8]. Moon considers the range and type of reflection within learning and professional development, arguing for an expanded role of reflection within Kolb's experiential learning cycle beyond the "reflective observation" phase [2]. This argument is in consideration to the reflective components of other phases exemplified in alternate conceptions of experiential learning. Abstract thoughts, not just concrete experiences, can be "experiences" upon which reflection can be directed. This view is consistent with Dewey's conception of reflective thinking [5]. Moon suggests that reflection is an important characteristic of students' approaches to learning and is operative in moving through stages of learning. Deeper approaches to learning and deeper levels of learning require reflective practice. Surface approaches to learning and surface levels of learning are characterized by little or no reflection.

How such reflection, whether deep or surface, is undertaken is described by Schön, and expanded by Rose, using a temporal perspective. Schön describes reflection as either reflectionon-action or reflection-in-action [4]. "Reflection-on-action" is looking back on an experience with the aim of learning from it. "Reflection-in-action" refers to processing and adapting from 
within an experience. Rose adds reflection-then-action to specify processing prior events to direct future choices [3].

There are a wide variety of reflective activities in professional practice that encompass and expand upon these conceptions of reflection [2]. Reflection is operative across professions but may have specific practices that are emphasized or are more natural to particular professions. Moon enumerates several conditions for reflection, such as, time and space, facilitators, supportive environments, purposes and outcomes, guidance, available scaffolding, and epistemological beliefs [2]. This study seeks to clarify the current uses of reflection by engineers and engineering learners to better understand how reflection is used within engineering and engineering education. Awareness and use of reflection are increasing within engineering and engineering education [13] but is largely missing within the discipline [15]. This study discusses how those in the discipline use reflection, both in their professional/academic and personal lives.

\section{Research Methods}

Sample: An online survey was distributed to faculty, students and practitioners to understand how engineers use reflection both in their professional practice and in their personal lives. Faculty and students surveyed were from four distinctly different institutions, while practitioners were identified from industry advisory boards, capstone project mentors, alumni, and colleagues. Responses were obtained from 460 respondents - 67 faculty, 267 students, and 93 practitioners. Researchers randomly selected a sample of 220 respondents (34 faculty, 141 students, and 45 practitioners) to analyze for this study.

Data Collection: The original survey consisted of five questions to better understand how each respondent defined reflection, used reflection in their daily, professional and/or academic lives, and how reflection was valued. Responses were collected using an online survey. The overall survey took approximately 5-10 minutes to complete. Accurate response rates are unknown given the means of distributing the survey; however, based on the authors' knowledge it seems that response rate was highest for practitioners, followed by faculty and students. The following study analyses responses to the following questions:

1. Write your definition of "reflection" (please do not provide a dictionary definition).

2. Provide examples of how you use reflection in your personal life.

3. Provide examples of how you use reflection in your professional or academic life.

Data Analysis: Analysis for this paper summarizes how respondents define reflection and use reflection in both their personal and professional/academic lives. An emergent set of codes for each question was determined by first having each of four researchers review and evaluate 22 identical responses to identify common words/phrases and predominate themes. The researchers 
Table 1: Codebook for personal and professional use of reflection with example responses.

\begin{tabular}{|c|c|c|}
\hline Codes & $\begin{array}{l}\text { Example Responses for Personal Use of } \\
\text { Reflection }\end{array}$ & $\begin{array}{l}\text { Example Responses for Professional } \\
\text { Use of Reflection }\end{array}$ \\
\hline $\begin{array}{l}\text { Remembering } \\
\text { /Monitoring } \\
\text { Progress }\end{array}$ & $\begin{array}{l}\text { "In my personal life, I sometimes reflect on news } \\
\text { or material I read for fun or on interpersonal } \\
\text { relationships." }\end{array}$ & $\begin{array}{l}\text { "Reviewing study techniques to see which } \\
\text { work and which don't" }\end{array}$ \\
\hline Improvement & $\begin{array}{l}\text { "I often think about whether things are going well } \\
\text { or not, and make adjustments to what I do based on } \\
\text { what I see looking at myself." }\end{array}$ & $\begin{array}{l}\text { "After lecturing, thinking about what } \\
\text { worked for me, what I think worked for } \\
\text { the students, and where I might improve." }\end{array}$ \\
\hline $\begin{array}{l}\text { Making } \\
\text { Meaning }\end{array}$ & $\begin{array}{l}\text { "I tend to reflect on interactions, thinking about } \\
\text { what promoted conversation and aiming to bring } \\
\text { that topic up again in the future." }\end{array}$ & $\begin{array}{l}\text { "I frequently take walks around the } \\
\text { building where I work and use that time } \\
\text { to get a fresh perspective about the task } \\
\text { on which I am working." }\end{array}$ \\
\hline Relationships & $\begin{array}{l}\text { "Talking to family members about where to live, } \\
\text { which career to pursue, who to associate with." }\end{array}$ & N/A \\
\hline $\begin{array}{l}\text { Setting/ } \\
\text { Keeping on a } \\
\text { Path }\end{array}$ & $\begin{array}{l}\text { "Time management and budget, primarily. To keep } \\
\text { myself and my family from over-committing in } \\
\text { either time or money." }\end{array}$ & $\begin{array}{l}\text { "I review my goals and accomplishments } \\
\text { on a yearly basis and realign my efforts" }\end{array}$ \\
\hline $\begin{array}{l}\text { Making } \\
\text { Decisions }\end{array}$ & $\begin{array}{l}\text { "I use reflection to consider what actions and } \\
\text { relationships I should look to keep in my life, and } \\
\text { which actions and relationships I should get rid of." }\end{array}$ & $\begin{array}{l}\text { "After tests, I look back on how much I } \\
\text { studied against my score and use that } \\
\text { information to make decisions regarding } \\
\text { changes in study habits." * }\end{array}$ \\
\hline Checklist & $\begin{array}{l}\text { "I reflect on the day I have each night and think of } \\
\text { what still needs to be done..." }\end{array}$ & $\begin{array}{l}\text { "On my morning walk, I think about the } \\
\text { tasks to complete and what is most } \\
\text { important." }\end{array}$ \\
\hline $\begin{array}{l}\text { Checking } \\
\text { Against } \\
\text { Morals }\end{array}$ & $\begin{array}{l}\text { "I often think back on interactions with friends and } \\
\text { family and ask myself if I was kind, thoughtful, - } \\
\text { ultimately-if I was what they needed at the time." }\end{array}$ & $\begin{array}{l}\text { "In a similar manner to ... my personal } \\
\text { life, I strive to apply many of my faith } \\
\text { vehicles to my professional life as well." }\end{array}$ \\
\hline $\begin{array}{l}\text { Emotional } \\
\text { Assessment }\end{array}$ & $\begin{array}{l}\text { "if I've gotten angry or upset about something, } \\
\text { once I've calmed down ... I reflect on the situation } \\
\text { and why I'm so angry. it helps me get over it when } \\
\text { I understand my feelings." }\end{array}$ & $\begin{array}{l}\text { "How certain interventions worked or } \\
\text { didn't work; my reactions to things in the } \\
\text { classroom." ** }\end{array}$ \\
\hline Spiritual & $\begin{array}{l}\text { "I am trying to meditate every day! That's been } \\
\text { really helping my stressful quarter." }\end{array}$ & $\begin{array}{l}\text { "When making critical decisions, I will } \\
\text { consider the consequences of my pending } \\
\text { actions, sometimes including the aspect of } \\
\text { prayer in my practical engineering } \\
\text { decisions." } * * *\end{array}$ \\
\hline
\end{tabular}

* Note: response coded as both monitoring progress and making decisions.

** Note: response coded as both monitoring progress and emotional assessment.

*** Note: response coded as both making decisions and spiritual; only one spiritual code in all professional use

then discussed the codes during multiple iterations to ensure inter-rater reliability; codes often evolved through these discussions. Each researcher subsequently coded approximately 100 
responses individually, such that each response was reviewed and coded by two researchers for a total of 200 additional responses. Difficult to code responses were discussed among all coders in two final discussions.

Codes used to code definitions remained consistent from our previous work [11]. Emergent codes for uses of reflection were emergent and are summarized by participant responses in Table 1. Most codes emerged in both contexts for reflection, i.e., personal and professional/academic, including making meaning, setting/keeping on a path, making decisions, checklist, checking against morals, emotional assessment, and spiritual. A few codes were similar in both groups, though slightly different in definition. For example, remembering was used in both types of reflection, but for professional use it was often to monitor progress. The improvement code was directed toward self-improvement in personal use while improvement was often attributed to a task, class, or project for professional use. Finally, the relationship code appeared only in personal use and focused on reflection with others. Definitions for each code evolved in the early discussions among researchers. Examples are displayed in Table 1. Some responses were coded using multiple codes.

\section{Results}

Definition of Reflection: Our previous work from 2017 analyzed how participants defined and valued reflection in their lives [11]. This analysis used a subset of 159 respondents (53 from each group) from the total sample of 458. A set of codes were used to help group how participants define reflection and their associated value of reflection. The following three primary codes emerged for definitions of reflection: 1) Looking Back (LB), 2) Apply to Present (AP), and 3) Affect the Future $(F)$. These responses align with the three models presented earlier describing the relationship between action and reflection. One additional code, Scientific Definition (SD), also emerged for those who mistook the prompt and provided scientific definitions of reflection.

We include the same analysis for this study to provide a foundation for the new sample of 220 respondents used in this study. All definitions of reflection were coded using one $(\sim 66 \%)$, two $(\sim 27 \%)$, or three $(\sim 6 \%)$ codes per response. The majority of responses keyed in on reflection as a way to look back on a past experience or event, followed by applying to the present and affecting the future. Table 2 compares the overall percentages from our previous sample with our new sample. Differences of note include a higher percentage of responses coded as looking back and less responses coded as applying to the present and affecting the future. Only a few responses in both samples used a scientific definition. 
Table 2: Total number of responses for each code defining reflection.

\begin{tabular}{|c|c|c|c|c|c|c|c|c|}
\hline \multirow{2}{*}{ Groups } & \multicolumn{2}{|c|}{ LB } & \multicolumn{2}{c|}{ AP } & \multicolumn{2}{c|}{ F } & \multicolumn{2}{c|}{ SD } \\
\cline { 2 - 9 } & $\mathbf{2 0 1 7}$ & $\mathbf{2 0 1 8}$ & $\mathbf{2 0 1 7}$ & $\mathbf{2 0 1 8}$ & $\mathbf{2 0 1 7}$ & $\mathbf{2 0 1 8}$ & $\mathbf{2 0 1 7}$ & $\mathbf{2 0 1 8}$ \\
\hline Faculty & $74 \%$ & $59 \%$ & $36 \%$ & $50 \%$ & $30 \%$ & $29 \%$ & $11 \%$ & $0 \%$ \\
\hline Students & $59 \%$ & $79 \%$ & $59 \%$ & $31 \%$ & $36 \%$ & $21 \%$ & $2 \%$ & $10 \%$ \\
\hline Practitioners & $64 \%$ & $64 \%$ & $51 \%$ & $51 \%$ & $32 \%$ & $20 \%$ & $4 \%$ & $4 \%$ \\
\hline
\end{tabular}

* $\mathrm{LB}=$ Looking Back, AP = Apply to Present, $\mathrm{F}=$ Affect the Future, SD = Scientific Definition.

An ANOVA analysis across the three groups previously revealed no significant differences. The new sample revealed significant differences for looking back $[F(2,219)=3.790, p=0.024]$ and applying to the present $[\mathrm{F}(2,219)=4.493, \mathrm{p}=0.012]$ (Table 3). A post hoc Tukey test revealed significant differences between students and faculty $(\mathrm{p}<0.05)$ for looking back and between practitioners and students for applying to the present $(\mathrm{p}<0.05)$.

Table 3: ANOVA analysis for responses regarding definitions of reflection

\begin{tabular}{|c|c|c|c|c|c|c|c|c|}
\hline & \multicolumn{2}{|c|}{ LB } & \multicolumn{2}{c|}{ AP } & \multicolumn{2}{c|}{ F } & \multicolumn{2}{c|}{ SD } \\
\cline { 2 - 9 } & $\mathbf{2 0 1 7}$ & $\mathbf{2 0 1 8}$ & $\mathbf{2 0 1 7}$ & $\mathbf{2 0 1 8}$ & $\mathbf{2 0 1 7}$ & $\mathbf{2 0 1 8}$ & $\mathbf{2 0 1 7}$ & $\mathbf{2 0 1 8}$ \\
\hline F & 1.360 & 3.790 & 2.869 & 4.493 & 0.248 & 0.678 & 2.505 & 2.356 \\
\hline $\mathbf{p}$ & 0.260 & $0.024 *$ & 0.060 & $0.012 *$ & 0.780 & 0.509 & 0.085 & 0.097 \\
\hline df & 2 & 2 & 2 & 2 & 2 & 2 & 2 & 2 \\
\hline
\end{tabular}

$*_{\mathrm{p}} \leq 0.05$

Personal and Professional Use of Reflection: The responses for each use of reflection were coded and tabulated to identify the prevalence of each code for the overall sample and each individual group - faculty, students, and practitioners. Each code was tallied to consider the number of times the code was used and by which group. Table 4 summarizes all codes based on total number by group for both personal and professional use.

Four codes were most prevalent among the three groups for personal uses of reflection. Students and practitioners identified the same two codes - Improvement (39\% and 43\%, respectively) and Making Meaning (33\% and 34\%, respectively) - as the top two cited codes. Faculty identified Making Meaning (29\%) as the top cited usage, but cited Improvement at a much lower rate (15\%). Making Decisions (21\%) was the second most cited usage for faculty and the third most cited usage for practitioners (20\%), but was referenced far fewer times by students $(8 \%)$. Similarly, Remembering was the third most cited usage for students $(12 \%)$ and faculty $(15 \%)$, while rarely referenced by practitioners (5\%). Note: faculty cited Remembering and Improvement 
Table 4: Percentages of participants within each group for all coded personal and professional uses of reflection. (Note: blue denotes the most cited use, followed by red and green as the second and third most cited, respectively.)

\begin{tabular}{|c|c|c|c|c|c|c|}
\hline \multirow{2}{*}{ Codes } & \multicolumn{3}{|c|}{ Personal Use } & \multicolumn{3}{|c|}{ Professional Use } \\
\hline & Students & Faculty & Practitioner & Students & Faculty & Practitioner \\
\hline Remembering/MP & $12 \%$ & $15 \%$ & $5 \%$ & $37 \%$ & $26 \%$ & $18 \%$ \\
\hline Improvement & $39 \%$ & $15 \%$ & $43 \%$ & $36 \%$ & $38 \%$ & $43 \%$ \\
\hline Making Meaning & $33 \%$ & $29 \%$ & $34 \%$ & $16 \%$ & $18 \%$ & $25 \%$ \\
\hline Making Decisions & $8 \%$ & $21 \%$ & $20 \%$ & $2 \%$ & $3 \%$ & $16 \%$ \\
\hline Path & $6 \%$ & $9 \%$ & $9 \%$ & $4 \%$ & $6 \%$ & $7 \%$ \\
\hline Spiritual & $8 \%$ & $6 \%$ & $11 \%$ & $0 \%$ & $0 \%$ & $2 \%$ \\
\hline Moral & $4 \%$ & $0 \%$ & $5 \%$ & $1 \%$ & $0 \%$ & $2 \%$ \\
\hline $\begin{array}{l}\text { Emotional } \\
\text { Assessment }\end{array}$ & $6 \%$ & $3 \%$ & $0 \%$ & $1 \%$ & $3 \%$ & $0 \%$ \\
\hline Relationships & $1 \%$ & $3 \%$ & $2 \%$ & \multicolumn{3}{|c|}{ N/A } \\
\hline Check & $1 \%$ & $3 \%$ & $0 \%$ & $0 \%$ & $6 \%$ & $0 \%$ \\
\hline Infrequent Use & $1 \%$ & $0 \%$ & $0 \%$ & $8 \%$ & $0 \%$ & $0 \%$ \\
\hline No Use & $1 \%$ & $0 \%$ & $0 \%$ & $1 \%$ & $3 \%$ & $0 \%$ \\
\hline No Code & $6 \%$ & $12 \%$ & $0 \%$ & $8 \%$ & $12 \%$ & $5 \%$ \\
\hline
\end{tabular}


at the same rate (15\%). All usages outside of the top three were cited less than $13 \%$.

Three codes - Monitoring Performance, Improvement, and Making Meaning - emerged as the dominant professional uses for all three groups. The order of importance varied for each group. All three groups cited Improvement as the most or close to mostly cited usage (36-43\%). Students cited Monitoring Performance (37\%) at a slightly higher rate than Improvement. Monitoring Performance was the second most cited usage for faculty (26\%), but less cited by practitioners (18\%). Making Meaning was identified as the second greatest use for practitioners (25\%), while students and faculty identified Monitoring Performance at slightly lower rates ( $16 \%$ and $18 \%$ respectively). All usages outside of the top three were cited less than $16 \%$.

Correlations between Definitions and Uses: A partial correlation analysis was conducted to reveal potential connections between respondents' definitions of reflection and their most cited uses for reflection in their personal and professional lives. Table 5 displays significant partial correlations between definitions and personal uses when controlling for group membership students, faculty and practitioners.

Table 5: Significant correlations between definitions of reflection and uses.

\begin{tabular}{|l|l|l|}
\hline Definitions of Reflection & Personal Uses & Professional Uses \\
\hline \multirow{2}{*}{ Looking Back } & $\begin{array}{l}\text { Making Meaning } \\
\mathrm{r}=0.144, \mathrm{p}=0.033\end{array}$ & $\begin{array}{l}\text { Improvement } \\
\mathrm{r}=0.224, \mathrm{p}=0.001\end{array}$ \\
\cline { 2 - 3 } & $\begin{array}{l}\text { Improvement } \\
\mathrm{r}=0.144, \mathrm{p}=0.033\end{array}$ & $\begin{array}{l}\text { Improvement } \\
\mathrm{r}=-0.142, \mathrm{p}=0.035\end{array}$ \\
\hline Applying to Present & $\begin{array}{l}\text { Making Decisions } \\
\mathrm{r}=0.121, \mathrm{p}=0.073^{*}\end{array}$ & $\begin{array}{l}\text { Improvement } \\
\mathrm{r}=0.204, \mathrm{p}=0.002\end{array}$ \\
\hline \multirow{2}{*}{ Affect the Future } & $\begin{array}{l}\text { Improvement } \\
\mathrm{r}=0.140, \mathrm{p}=0.038\end{array}$ & \\
\hline
\end{tabular}

$*$ not significant at $\mathrm{p} \leq 0.05$, but included due to close proximity

\section{Discussion}

This study sought to identify the definitions of reflection and how individuals use reflection in two different contexts: personal settings and professional/academic settings. These results were then subdivided across three groups associated within engineering: students, faculty and practitioners. The same codes emerged for all three groups when assessing definitions of reflection. These codes are also in close alignment with definitions of reflection postulated by Schön [4] and Rose [3]. The results provide empirical evidence for the theoretical constructs.

When examining the definitional data from a sub-sample of respondents (159 out of 458) analyzed in 2017, the authors found no statistical differences between respondent groups; 
however, when looking at a slightly larger set of respondents (220 out of 458), significant differences began to emerge. Most notably, students were less likely to define reflection as applying reflective thought to present circumstances, or what Schön described as reflection-inaction. Students were far more likely to use reflection to look back on prior experiences, or reflection-on-action. Faculty and practitioners were about equally likely to use these two definitions of reflection. One might speculate that both faculty and practitioners are more experienced in facing challenging situations, which would benefit from reflection-in-action compared to students. They are therefore more likely to consider this mode of reflection in their own definitions.

Use of reflection in personal settings provided some interesting results when comparing across respondent groups. First, students and practitioners saw using reflection to achieve personal improvement as the most dominant way in which to use reflection. Some faculty saw this use of reflection as important as well, but at much lower rates. The most important use of reflection for faculty was making meaning of past events. It's not immediately clear why these differences exist. What is clear is that practitioners viewed reflection as a way to improve themselves as people and as professionals. This result may be important in achieving the authors' overall goal of understanding faculty and practitioners' effective use of reflection so as to better prepare students to use reflection in their future engineering careers. It is also worth noting that both improvement and meaning making are cited by all three respondent groups as being among the most important uses of reflection. This would seem to suggest that despite some differences in the rank order and rate of use, a focus on how reflection can lead to improvement and help make meaning of past events is important for all respondents to this survey regardless of their level of experience in engineering.

Second, faculty and practitioners cite using reflection to help make decisions at nearly the same rate ( $21 \%$ and $20 \%$ respectively). This implies that for individuals with greater experience and perhaps responsibility as working engineers, the use of reflection as a tool for making decisions becomes much more important. A challenge will be conveying to students this important use of reflection, as only $8 \%$ of student respondents considered this form of use.

Finally, it is important to note that remembering is a moderately important use of reflection for both students and faculty, but not for practitioners. Keep in mind that remembering implies looking back upon past events without actually attempting to make meaning from it. Why students and faculty would be more prone to use this relatively passive form of reflection is unclear. Perhaps there is something about working in industry that pushes practitioners to see reflection as a precious commodity, not to be wasted with passive behavior.

Within the context of the professional/academic setting there were fewer differences among the respondent groups. All three groups cited the same three codes - making meaning, monitoring 
progress, and improvement - as the most important to use. This suggests that engineers at all stages see these three aspects of reflection as most crucial to their professional responsibilities and success. It will be important to convey to students when promoting reflection in the classroom that these uses will continue to serve them into their future careers.

An interesting finding within the context of professional/academic use is how the rate of use of remembering/monitoring progress declines from students to faculty to practitioners. This is the most common use of reflection by students, attesting to the academic environment in which they operate and the intense pressure they feel to obtain good grades. Faculty too are likely to see remembering/monitoring progress as a common use, perhaps especially those who have yet to obtain tenure or a promotion in rank. Practitioners see remembering/monitoring progress as important too, but at less than half the rate of students. One might conclude based on this trend that practitioners are more focused on extending their reflection time beyond simply understanding where they are at in their careers or on a project. They prefer to proactively seek ways to move beyond this state and improve upon their situation. Such active reflection might be important to convey to students who seem more focused on the more passive mode of simply monitoring their progress within a class without identifying ways to improve.

This study also conducted correlational analysis between definitions of use and likelihood of using reflection in a particular way in either setting. There were few statistically significant correlations, and those that were significant were not large $(r<0.25)$. The definition of reflection as looking back, did tend to correlate with personal uses of reflection making meaning and improvement. This correlation may be statistically significant simply because all three respondent groups saw looking back as the most prevalent definition of reflection and making meaning and improvement as prevalent uses.

Applying to present was weakly correlated with making decisions (though not at the $\mathrm{p} \leq 0.05$ level), which is probably due to the propensity of faculty and practitioners to define reflection as applying to present and also citing making decisions as a top three personal use of reflection. This is not all that surprising as one would assume that when trying to make decisions, respondents would be more likely to think of reflection as a process of thinking about present circumstances.

An additional correlation within the personal use setting was seen between defining reflection as affecting the future and using reflection for improvement. The correlation is likely a result of all three respondent groups defining reflection as affecting the future and improvement as a top three personal use. This suggests that for the respondents in this study, using reflection as a means to personal improvement is an activity that is future forward. 
The final correlation, which was within the context of professional/academic use, was improvement with all three definitions of reflection. This is probably due to the fact that improvement was practically the highest cited professional use for all respondent groups. What is interesting is that applying to present is negatively correlated with improvement. This implies that those who see reflection as applying to their present circumstances are less likely to use reflection for professional or academic improvement. This may be because students were less likely to see applying reflection to the present as a way to define reflection compared to both faculty and practitioners.

\section{Limitations}

There are a few potential limitations to the present study. First is the limited data size for each group of participants. The complete data set containing 460 participants included only 67 faculty members. This is further reduced by the authors' decision to randomly select 220 respondents for qualitative analysis. This step was necessary in order to make the data set manageable; however, it had the effect of reducing the faculty sample to an even smaller size of 34 faculty members. The analysis included slightly less than half of respondents within this one group. We believe our sample size is sufficient to provide an identification of the coded responses and their rough rankordering despite this limitation.

A second limitation lies within the means of data collection. The use of an online survey may very well have biased who did and did not respond to the survey. The mode of survey delivery may have led to shorter and less thoughtful responses from some respondents than might have been possible with data collection methods that sequester more of the respondents' time and attention, such as focus groups or semi-structured interviews. This approach was taken to capture as much data as possible for this preliminary study, while attempting to overcome significant challenges in trying to work with practitioners and faculty at many diverse locations. An online survey delivery mode was the most practical and feasible option for this study.

Finally, the sample used in this study was a sample of convenience. There is no claim that the results presented here are in fact representative of or generalizable to the broader population of faculty, practitioners and students in engineering. This is particularly true of the practitioner sample, which was recruited from a population of individuals known to the researchers through a variety of different channels, including alumni. A related limitation is that the actual respondents were somewhat biased toward those who were interested in engineering education and/or thought of themselves already as someone who is reflective, i.e., those who see themselves as reflective are more likely to complete the survey about reflection. 


\section{Conclusions \& Implications}

Reflection demonstrated by engineering students, faculty and practitioners within their personal and professional/academic lives revealed a consistent set of uses across the three groups. This contradicts the broad belief that faculty think students don't appreciate reflection. Using reflection to remember or monitor progress, improve, make meaning, or make decisions was cited by all three groups for both reflection settings. The rate at which each was cited across the groups varied, which suggests a need for better alignment between education and practice. The findings of this study support potential changes in how reflection is learned and later practiced by engineering learners. Faculty need to become better aware of how students utilize reflection in an academic setting in order to prepare them for the professional use of reflection. Such efforts should be made in a way that supports personal use. The following study provides a foundation for future work investigating change efforts that aim to increase faculty and engineering students' learning of reflection as a professional engineering skill and their associated reflective practice within teaching, learning, and engineering work. Changes made within an educational environment have the potential to improve how students reflect, which will help students learn how to use reflection effectively in the workplace and positively impact reflection in practice.

\section{Acknowledgement}

This material is based on work supported by The Leona M. and Harry B. Helmsley Charitable Trust through funding of the Consortium to Promote Reflection in Engineering Education (CPREE), a collaboration of twelve educational institutions http://cpree.uw.edu.

\section{References}

[1] J. Dewey, How We Think. San Bernardino, CA: Renaissance Classics, 2012 (reprint of 1910 original).

[2] J. A. Moon, Reflection in learning and professional development: Theory and practice. London, England: Routledge Falmer, 1999.

[3] E. Rose, On reflection: An essay on technology, education, and the status of thought in the Twenty-first century. Toronto, Canada: Canadian Scholar's Press Inc., 2013.

[4] D. A. Schön, D. A., The reflective practitioner: How professionals think in action (Vol. 5126). New York, NY: Basic books, 1983.

[5] C. Rodgers, "Defining reflection: Another look at John Dewey and reflective thinking," The Teachers College Record, vol. 104, no. 4, pp. 842-866, 2002.

[6] S. Brookfield, Becoming a Critically Reflective Teacher. San Francisco, CA: Jossey-Bass, 1995.

[7] J. A. Mezirow \& Associates, Fostering critical reflection in adulthood. San Francisco, CA: Jossey-Bass, 1990. 
[8] R. Grossman, "Structures for facilitating student reflection," College Teaching, vol. 57, no. 1, pp. 15-22, 2009.

[9] K. Csavina, A. Carberry and C. Nethken, "Assessing student understanding of reflection in engineering education," in Proceedings of the American Society for Engineering Education Annual Conference \& Exposition, New Orleans, LA, USA, June 26-29, 2016.

[10] K. Csavina, A. Carberry and C. Nethken, "Understanding perceptions of reflection among engineering educators and students," International Journal of Engineering Education, vol. 33, no. 5, pp. 1534-1542, 2016.

[11] K. Csavina, A. Carberry, P. Cunningham and T. Harding, "Work in progress: Examining the value of reflection in engineering practice and education," in Proceedings of the American Society for Engineering Education Annual Conference \& Exposition, Columbus, OH, USA, June 25-28, 2017.

[12] T. Harding, K. Chen, L. Vanasupa, L. Domingo, K. Colvin, A. Pande, T. Kawahara, L. Slivovsky, S. Peuker, J. Widman, and P. Schuster, "The role of collaborative inquiry in transforming faculty perspectives on use of reflection in engineering education," in Proceedings of Frontiers In Education Annual Conference, El Paso, TX, USA, October 2124, 2015.

[13] L. A. Sepp, M. Orand, J. A. Turns, L. D. Thomas, B. Sattler and C. J. Atman, "On an upward trend: Reflection in engineering education," in Proceedings of American Society for Engineering Education Annual Conference \& Exposition, Seattle, WA, USA, June 14-17, 2015.

[14] S. Summers, H. Chenette, E. Ingram, J. McCormack and P. Cunningham, "CrossDisciplinary Exploration and Application of Reflection as a High Impact Pedagogy," Insight: A Journal of Scholarly Teaching, vol. 11, pp. 29-47, 2016.

[15] J. A. Turns, B. Sattler, K. Yasuhara, J. L. Borgford-Parnell, and C. J. Atman, "Integrating reflection into engineering education," in Proceedings of American Society for Engineering Education Annual Conference \& Exposition, Indianapolis, IN, USA, June 15-18, 2014.

[16] J. A. Turns, B. Sattler, L. D. Thomas, C. J. Atman, R. B. Bankhead, A. R. Carberry, K. R. Csavina, P. J. Cunningham, D. K. Faust, T. S. Harding and K. Yasuhara, "Reflecting on reflection. How educators experience the opportunity to talk about supporting student reflection," in Proceedings of American Society for Engineering Education Annual Conference \& Exposition, Seattle, WA, USA, June 14-17, 2015.

[17] D. A. Kolb, Learning style inventory technical manual, Boston, MA: McBer, 1976.

[18] J. Zull, The art of changing the brain: Enriching the practice of teaching by exploring the biology of learning, Sterling, VA: Sylus, 2002.

[19] B. Zimmerman, "Becoming a self-regulated learning: An overview," Theory Into Practice, vol. 41, no. 2, pp. 64-70, 2002. 